\title{
Effect of eight months of inhaled beclomethasone dipropionate and budesonide on carbohydrate metabolism in adults with asthma
}

\author{
Kirsti Kiviranta, Markku Turpeinen
}

\begin{abstract}
Background-The safety of high dose inhaled steroids has been a subject of debate. The efficacy and safety of beclomethasone dipropionate and budesonide inhalations were evaluated by measuring their effects on pulmonary function, on the hypothalamic-pituitaryadrenocortical axis, and on carbohydrate metabolism in adults with unstable asthma.

Methods-Fifteen adults with unstable asthma and 15 healthy controls were studied. Eight patients were treated with beclomethasone dipropionate in initially high (2 mg/day for five months) and subsequently lower (1 mg/day for three months) doses. Seven patients were treated with budesonide at doses of 1.6 mg/day for five months followed by 0.8 mg/day for three months. Blood glucose and serum insulin were measured in an oral glucose tolerance test and plasma cortisol in an adrenocorticotrophic hormone test. The antiasthmatic effect of treatment was evaluated by measuring peak morning expiratory flow rates and forced expiratory volume in one second (FEV 1 ).
\end{abstract}

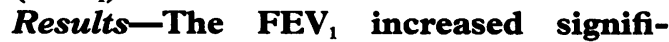
cantly after one month of treatment (medians 88\% v 96\%, p $<0.01$ ), and nocturnal symptoms disappeared within two weeks of treatment in both groups. At one month, the high dose significantly decreased serum insulin concentrations as calculated from the areas under the incremental two hour curves in the glucose tolerance test. The decrease was $59 \%$ for beclomethasone dipropionate (medians $76 v 31 \mathrm{mU} / \mathrm{/h} / \mathrm{h}, \mathrm{p}<0.005$ ) and $42 \%$ for budesonide (medians $79 v 46$ mU/1/h, $p<0.01)$. The median areas at five and eight months were intermediate for both drugs. No significant differences were found when the five and eight month values were compared either with the baseline or with one month values. The difference between the baseline values of both groups and the respective values in healthy controls was significant (medians $79 v 49 \mathrm{mU} / \mathrm{/h}, \mathrm{p}<0.01$ ). The one month values for the patients and control subjects were similar. Paralleling the changes for insulin, the area under the incremental two hour blood glucose curve decreased significantly (medians

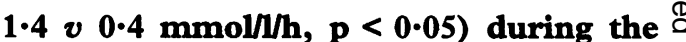
first month of treatment. The five and $\%$ eight month values were intermediate $\vec{\circ}$ (medians 0.8 and $0.7 \mathrm{mmol} / \mathrm{h} / \mathrm{h}$, respectively). These changes were not significant compared with the baseline or the one month areas. Similar changes were seen in both treatment groups. Neither $\stackrel{\oplus}{\circ}$ treatment had any significant effect on $\overrightarrow{0}$ plasma cortisol in the one hour adrenocorticotrophic hormone test.

Conclusions-In patients stressed by 은 uncontrolled asthma, the antiasthmatic effect of high dose beclomethasone dipropionate and budesonide was accompanied by a significant initial $\stackrel{\oplus}{\sim}$ decrease in insulin resistance with a par- $\overrightarrow{0}$ allel improvement in glucose tolerance. During prolonged treatment a small $\square$ increase in insulin sensitivity was found. The overall effect of beclomethasone dipropionate and budesonide inhalations on carbohydrate metabolism may be beneficial in patients with uncontrolled asthma.

(Thorax 1993;48:974-978)

Inhaled glucocorticoids are highly effective in $\stackrel{0}{x}$ the treatment of asthma and they are now recommended even in the early stages of newly detected disease. ${ }^{1}$ The antiasthmatic effect of inhaled glucocorticoids is, however, associated with dose related systemic $\stackrel{9}{工}$ effects. ${ }^{23}$ Decreased insulin sensitivity, with- $\frac{D}{O}$ out significant effects on glucose tolerance or cortisol secretion, has been found in healthy $\mathrm{N}$ adults inhaling beclomethasone $(1 \mathrm{mg} /$ day for $\mathrm{N}$ one month) ${ }^{4}$ and in children with asthma N inhaling budesonide $\left(0.8 \mathrm{mg} / \mathrm{m}^{2} /\right.$ day for one month). ${ }^{5}$ The purpose of the present study was to evaluate the efficacy and safety of beclomethasone dipropionate and budesonide inhaled in high dosage during a longer treatment period. We report the effects on pulmonary function, on the hypothalamic- $\stackrel{D}{\Omega}$ pituitary-adrenocortical axis, and on carbo- $\triangle$ hydrate metabolism in adults with unstable asthma.

\section{Methods}

SUBJECTS

Ten women and five men with asthma were studied. Their ages ranged from 18 to 56 (mean 33.7) years, and the duration of asth- 
Table 1 Clinical characteristics of patients and control subjects. Values are medians (range)

\begin{tabular}{|c|c|c|c|}
\hline & \multicolumn{2}{|l|}{ Patients } & \multirow{2}{*}{$\begin{array}{l}\text { Control } \\
\text { subjects }\end{array}$} \\
\hline & $B D P$ & $B U D$ & \\
\hline \multicolumn{4}{|l|}{ Sex: } \\
\hline F & 5 & 5 & 10 \\
\hline M & 3 & 2 & 5 \\
\hline Age (years) & $\begin{array}{l}34 \\
(26-56)\end{array}$ & $\begin{array}{l}26 \\
(18-48)\end{array}$ & $\begin{array}{l}36 \\
(19-57)\end{array}$ \\
\hline $\begin{array}{l}\text { Body mass index } \\
\left(\mathrm{kg} / \mathrm{m}^{2}\right)\end{array}$ & $\begin{array}{l}24 \\
(18-33)\end{array}$ & $\begin{array}{l}26 \\
(21-34)\end{array}$ & $\begin{array}{l}23 \\
(19-30)\end{array}$ \\
\hline $\begin{array}{l}\text { Duration of } \\
\text { asthma (years) }\end{array}$ & $\begin{array}{l}0 \cdot 7 \\
(0 \cdot 25-5 \cdot 0)\end{array}$ & $\begin{array}{l}0.25 \\
(0.08-1 \cdot 0)\end{array}$ & - \\
\hline $\begin{array}{l}\mathrm{FEV}_{1} \\
\text { (\% predicted })\end{array}$ & $\begin{array}{l}80 \\
(70-110)\end{array}$ & $\begin{array}{l}94 \\
(54-108)\end{array}$ & - \\
\hline
\end{tabular}

BDP—beclomethasone dipropionate; BUD—budesonide.

matic symptoms ranged from one month to five years. The diagnosis of asthma was based on a positive history combined with bronchial hyperreactivity in a histamine challenge test. ${ }^{6}$ Their asthma was unstable. Eleven patients had nocturnal symptoms. Thirteen patients inhaled $\beta_{2}$ agonists regularly, and one of them was also taking slow release oral theophylline. No subject had taken any glucocorticoids previously.

All the patients were admitted to hospital for a baseline period of three to seven days. On the first hospital day, peak expiratory flow (PEF) was measured every six hours and thereafter in the morning and evening before and after inhaled $\beta_{2}$ agonists. Diurnal variation of PEF ranged from $8 \%$ to $51 \%$ (median $25 \%)$.

The patients were randomised into two treatment groups: eight patients were treated with beclomethasone dipropionate and seven patients with budesonide. Table 1 presents the clinical characteristics of these groups. A glucose tolerance test was also performed on 15 healthy controls matched for age, sex, and body mass index (table 1 ).

Informed consent was obtained from all patients. The study protocol was approved by the ethics committee of the department.

\section{STUDY DESIGN}

Inhaled $\beta_{2}$ agonists and oral theophylline were continued at the dosage already used. The daily dose varied from 0.4 to $0.8 \mathrm{mg}$ for salbutamol (beclomethasone dipropionate group) and from 1.0 to $2.0 \mathrm{mg}$ for terbutaline (budesonide group). Each patient was studied on four occasions: before treatment, and after one month, five months, and eight months of treatment. During the first treatment period of five months, eight patients were treated with beclomethasone dipropionate at a daily dose of $2 \mathrm{mg}$ divided into morning and evening doses. Seven patients were treated with budesonide at a daily dose of $1.6 \mathrm{mg}$ also divided into morning and evening doses. After five months of treatment the beclomethasone dipropionate dose was reduced to $1 \mathrm{mg} /$ day and the budesonide dose to $0.8 \mathrm{mg} /$ day divided into two doses for the next three months. Beclomethasone dipropionate and budesonide were inhaled from a metered dose inhaler with a "spacer" device (Volumatic, Glaxo, London, UK or Nebuhaler, Draco AB, Lund, Sweden). After inhalation the patients rinsed their mouths. The patients used a standard diary card to record symptoms of asthma and any additional use of $\beta_{2}$ agonists. The doses of $\beta_{2}$ agonists had to be stable (the same dosage as at the baseline) during the seven days before the tests. At each examination, they were admitted to the ward at 8.00 am after a 10 hour overnight fast. All treatment was stopped for 12 hours before the tests.

\section{ASSESSMENT}

The blood samples for determination of blood glucose, glycosylated haemoglobin, plasma cortisol, and serum insulin were taken between 8.00 and $9.00 \mathrm{am}$. The patients were given $75 \mathrm{~g}$ glucose orally in a volume of $300 \mathrm{ml}$. Blood samples for glucose and insulin determinations were obtained 60 and 120 minutes after oral glucose. Thereafter $0.25 \mathrm{mg}$ synthetic tetracosactide (S-Cortophin, NV, Organon, Oss, The Netherlands)

Table 2 Metabolic characteristics before treatment, after one and five months at high dosage, and a further three months at lower dosage of beclomethasone $(n=8)$ or budesonide inhalations $(n=7)$ in patients with asthma. Values are medians (range).

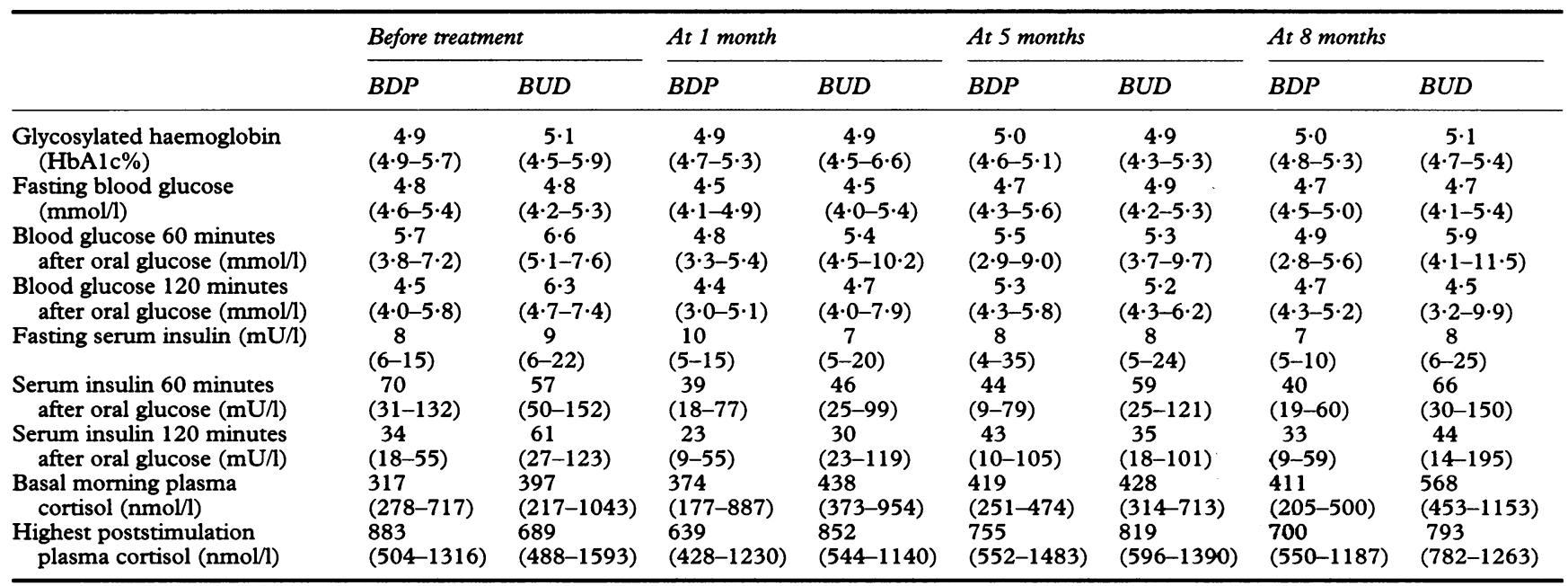

BDP—beclomethasone dipropionate; BUD—budesonide. 
Figure 1 Incremental areas of blood glucose in the oral glucose test before treatment, after one and five months at high

dosage, and after a further three months at lower dosage of beclomethasone dipropionate $(A, n=8)$ or budesonide $(B, n=7)$ inhalations, and in 15 healthy controls. At one month, the incremental areas decreased

significantly $(p<0.05)$ when the two groups were analysed together. The five and eight month values were intermediate; $x---x$, median.

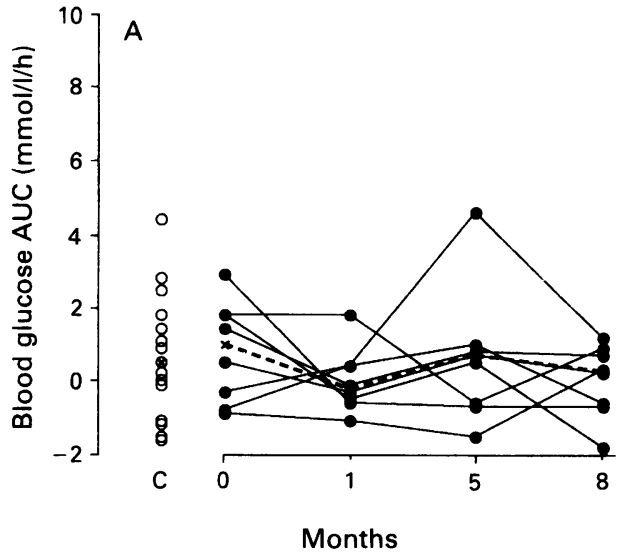

was administered as an intramuscular injection. Blood samples for cortisol determination were obtained 30 and 60 minutes after the injection. ${ }^{7}$ Criteria for adrenocortical suppression were an increment in plasma cortisol concentration $<150 \mathrm{nmol} / 1$ and the highest poststimulation plasma cortisol concentration $<400 \mathrm{nmol} / 1$. These limits represent the geometric fifth percentiles of the values for 37 healthy adults examined in our laboratory.

Blood glucose was measured by a glucose dehydrogenase method. ${ }^{8}$ The day to day coefficient of variation (CV) was $2 \cdot 4 \%$. Glycosylated haemoglobin (GHbA1C) was measured with a Diamat analyser (Bio-Rad Laboratories, Richmond, California, USA). Serum insulin was measured by radioimmunoassay (RIA; Phadeseph insulin RIA, Pharmacia Diagnostics AB, Uppsala, Sweden). The sensitivity of the assay was $<2.5 \mu \mathrm{g} / \mathrm{ml}$. Cross reactivity with $\mathrm{C}$ peptide was $<0 \cdot 1 \%$. Plasma cortisol concentrations were determined with a cortisol ( ${ }^{125 I)}$ RIA kit (Farmos Diagnostica, Turku, Finland). The cortisol antiserum used in the assay shows negligible cross reactivity with other endogenous corticosteroids and cortisol metabolites. The sensitivity of the assay was 3 to 5 $\mathrm{nmol} / \mathrm{l}$. Body mass index was calculated as weight $(\mathrm{kg}) / \mathrm{height}^{2}\left(\mathrm{~m}^{2}\right)$. Pulmonary function was studied with a dry bellows spirometer (Vitalograph Ltd, Buckingham, UK).

\section{STATISTICAL ANALYSIS}

The results are presented for each patient or as medians (range). Statistical comparisons within the treatment groups were performed with Friedman's non-parametric analysis of variance. $^{9}$ The groups were compared with Wilcoxon's test for unpaired data. The areas under the incremental blood glucose and serum insulin curves were calculated by the trapezoidal rule. ${ }^{10}$

\section{Results}

A rapid increase was found in the basal morning PEF in both treatment groups. This increase was $19 \%$ for beclomethasone dipropionate (median percentage of predicted $79 \% v 94 \%, \mathrm{p}<0.05)$ and $17 \%$ for budesonide $(69 \%$ v $81 \%$; $<<0.05)$ after one day

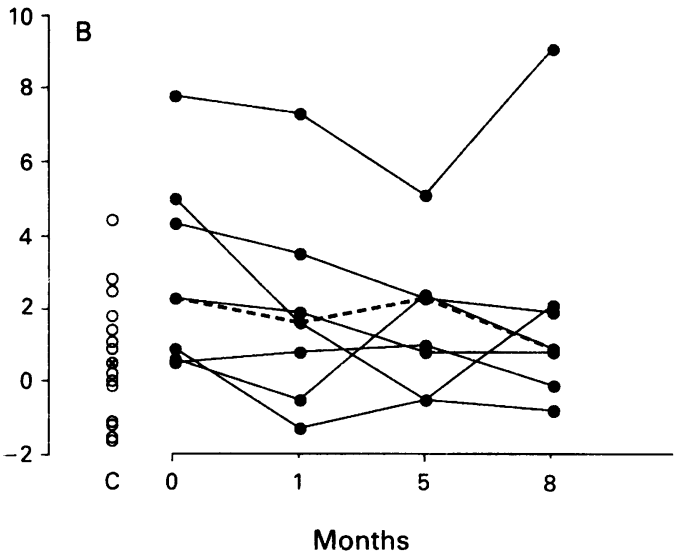

of treatment. At 20 days the median PEF was $94 \%$ for beclomethasone dipropionate ( $p<$ $0.05)$ and $96 \%$ for budesonide $(p<0.05)$. After one month of treatment, the median $\mathrm{FEV}_{1}$ as a percentage of the predicted value increased from $88 \%$ to $96 \%(p<0.01)$ when both groups were analysed together. At five months the value was $96 \%(\mathrm{p}<0.05)$ and at eight months it was $92 \%$ (NS).

In both groups, nocturnal symptoms disappeared after two weeks of treatment, and no additional $\beta_{2}$ agonist was needed apart from temporary use during acute respiratory infections. In all the patients, the dosage of $\beta_{2}$ agonists had been at the baseline level, at least during the seven days before the tests

Table 2 shows the metabolic changes during treatment. No significant changes occurred in the fasting blood glucose concentrations. In both treatment groups the individual values were normal $(<6.7 \mathrm{mmol} / \mathrm{l}){ }^{1}$ The fasting serum insulin concentration did not change during treatment. Neither blood glucose nor serum insulin concentrations in the glucose tolerance test were significantly affected by beclomethasone dipropionate or budesonide. Impaired glucose tolerance (two hour blood glucose 6.7 to $10 \mathrm{mmol} / \mathrm{l})^{11}$ was found in one patient at baseline and at one and eight months. Blood glycosylated haemoglobin did not change significantly during treatment.

At one month, the area under the incremental two hour blood glucose curve decreased significantly (medians $1.4 \quad v \quad 0.4$ $\mathrm{mmol} / \mathrm{l} / \mathrm{h}<0.05$; fig 1 ) when both groups were analysed together. The five and eight month values were intermediate (medians 0.8 and $0.7 \mathrm{mmol} / 1 / \mathrm{h}$, respectively). These changes were not significant when compared either with the baseline or with one month values.

In both treatment groups, the high dose significantly decreased the areas under the incremental two hour insulin curves at one month (fig 2). The decrease was $59 \%$ for beclomethasone (respective medians $76 v 31$ $\mathrm{mU} / \mathrm{l} / \mathrm{h}, \mathrm{p}<0.005$ ) and $42 \%$ for budesonide (respective medians $79 v 46 \mathrm{mU} / 1 / \mathrm{h}$, $\mathrm{p}<0.01)$. The areas at five and eight months were intermediate both for beclomethasone dipropionate (medians 46 and $47 \mathrm{mU} / \mathrm{l} / \mathrm{h}$ ) 
Figure 2 Incremental areas of serum insulin in the oral glucose test before treatment, after one and

five months of high dosage, and after a further three months at lower dosage of beclomethasone

dipropionate $(A, n=8)$ or budesonide ( $B, n=7)$ inhalations and in 15 healthy controls.

Significant decreases

occurred in both treatment groups at one month $(p<$ 0.005 for beclomethasone dipropionate, $p<0.01$ for budesonide). The five and eight month values were intermediate: $x--x$, median.
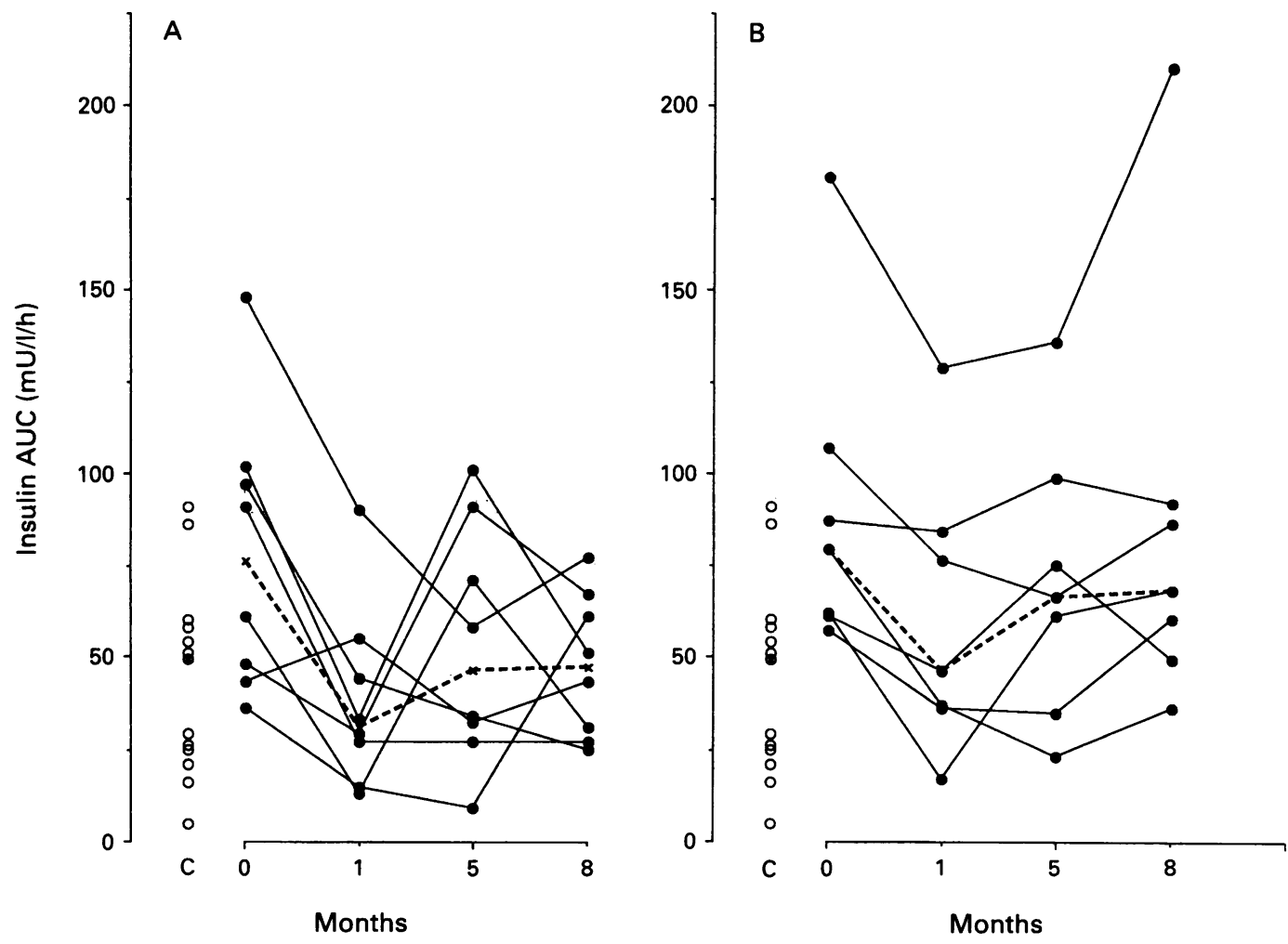

and for budesonide (medians 66 and 68 $\mathrm{mU} / \mathrm{h} / \mathrm{h}$, respectively). No significant differences were seen when the five and eight month values were compared with either the baseline or with the one month values. The values between the beclomethasone dipropionate and budesonide groups did not differ significantly. The difference between the baseline values in both groups $(n=15)$ and the respective values in controls $(n=15)$ was significant (medians 79 v $46 \mathrm{mU} / \mathrm{l} / \mathrm{h}$, $\mathrm{p}<0.01$ ). The one month values between the patients and controls did not differ (medians $37 v 49 \mathrm{mU} / \mathrm{l} / \mathrm{h}$, fig 2). Neither the basal nor the maximal poststimulation serum cortisol concentrations in the ACTH test were significantly affected by the treatment (table 2).

\section{Discussion}

These data show, in accordance with previous studies, ${ }^{112}$ that both beclomethasone dipropionate and budesonide are highly effective for the treatment of asthma. Improvement in pulmonary function was rapid and was detectable after one day of treatment. Clinically, the nocturnal symptoms disappeared within two weeks of treatment. The rapid response could be explained by the high doses used at the beginning of the study. This control was maintained on the lower dose. No serious adverse effects were seen during treatment. Neither beclomethasone dipropionate nor budesonide had any significant effect on cortisol secretion. Similar changes in carbohydrate metabolism were seen in the two treatment groups.

Sensitivity to insulin may be influenced by several factors such as age, body mass, and genetics. The large interindividual variation in insulin concentration in both controls and patients could be explained by these factors. We matched the controls for age, sex, and body mass to reduce the differences between patients and controls. In patients with asthma, both the medication and the stress due to the uncontrolled disease may affect carbohydrate metabolism. Standard doses of aerosol $\beta_{2}$ agonist do not affect plasma insulin concentrations but may produce a small transient increase in blood glucose. ${ }^{13}$ This effect on carbohydrate metabolism may be more pronounced in patients with unstable asthma because of increased concentrations of endogenous catecholamines. Therefore, we did not change the regular dosage of $\beta_{2}$ agonists during the study. The pretreatment areas under the incremental two hour serum insulin curves in the glucose tolerance test were significantly higher in the patients with asthma than in the healthy controls. Possibly this difference was largely the result of stress due to uncontrolled asthma; all the patients had daily symptoms before treatment with glucocorticoids. By contrast with previous reports, ${ }^{45}$ the high dose led to decreased insulin concentrations at one month, these concentrations being equal to those of the controls.

At five months there was a small decrease in insulin sensitivity. By contrast with previous results, ${ }^{5}$ no significant changes in insulin concentration were found during the next three months although the dose was lowered. These changes in insulin response were paralleled by changes in areas under the incremental blood glucose curves. Increased insulin concentrations have been found in 
healthy adults inhaling $1 \mathrm{mg}$ beclomethasone dipropionate a day for one month ${ }^{4}$ and in children with asthma inhaling $0.8 \mathrm{mg} / \mathrm{m}^{2}$ budesonide a day for one month. ${ }^{5}$ The discrepancy between these studies and the present results might be explained by the difference in the selection of subjects. Our patients were stressed by the disease and had higher insulin concentrations at the baseline than healthy adults ${ }^{4}$ or children with asthma. ${ }^{5}$ Thus the changes in insulin sensitivity seem more likely to depend on the stress caused by uncontrolled asthma than on a systemic effect of glucocorticoids.

In conclusion, high doses of inhaled beclomethasone dipropionate and budesonide produced a rapid antiasthmatic effect in adults with unstable asthma. Decreased sensitivity to insulin was found in these patients before treatment with glucocorticoids. The antiasthmatic effect was accompanied by a significant early decrease in insulin resistance with a parallel improvement in glucose tolerance. During prolonged treatment a slight decrease in insulin sensitivity was found. These findings suggest that the overall effect of beclomethasone dipropionate and budesonide inhalations on carbohydrate metabolism is beneficial in patients with uncontrolled asthma.

This study was supported by grants from the Ida Montin Foundation and the Allergy Research Foundation of Finland.
1 Haahtela $T$, Järvinen $M$, Kava $T$, Kiviranta $K$, Koskinen $\mathrm{S}$, Lehtonen $\mathrm{K}$, et al. Comparison of beta ${ }_{2}$-agonist terbutaline, with an inhaled corticosteroid, budesonide, in newly detected asthma. N Engl f Med 1991;325 388-92.

2 Law CM, Honour JW, Marchant JL, Preece MA, Warner JO. Nocturnal adrenal suppression in asthmatic children taking inhaled beclomethasone dipropionate. Lancet taking inhaled

3 Wolters $\mathrm{O}$, Pedersen S. Growth of asthmatic children during treatment with budesonide: a double blind trial. ? BMF 1991;303:163-5.

4 Kruszynska YT, Greenstone M, Home PD. Effect of high dose inhaled beclomethasone dipropionate on carbohydrate and lipid metabolism in normal subjects. Thorax 1987;42:881-4.

5 Turpeinen $M$, Sorva R, Juntunen-Backman K. Changes in carbohydrate and lipid metabolism in children with asthma inhaling budesonide. $\mathcal{F}$ Allergy Clin Immunol 1991;88:384-9.

6 Sovijärvi A, Reinikainen K, Rytilä P, Poppius H. A new dosimetric method for histamine challenge-repeata- $\vec{O}$ bility and clinical discriminatory power. Eur Respir $\mathcal{f}$ 1990;3(suppl 10):359-60.

7 Maynard DE, Folk RL, Riley TR, Wieland RG, Gwiup G, Harmwi GJ. A rapid test for adrenocortical insufficiency. Ann Intern Med 1966;64:552-6.

8 Banauch D, Brummer W, Ebeling W. A glucose dehydrogenase for the determination of glucose concentrations in body fluids. F Clin Chem Clin Biochem 1975;13: 101-7.

9 Dixon WJ. BMDP statistical software manual. Berkeley: University of California Press, 1988:424-5.

10 Lentner C. Geigy scientific tables. Basel: Ciba-Geigy Ltd, 음 1982;2:178.

11 Marble A, Ferguson BD. Diagnosis and classification of $\overrightarrow{0}$ diabetes mellitus and the nondiabetic meliturias. In: Marble A, Krall LP, Bradley RF, Christlieb AR, Soeldner JS, eds. Foslin's diabetes mellitus. Philadelphia: Lea and Febiger, 1985:332-52.

12 Meltezer EO, Kemp JP, Welch MJ, Orgel HA. Effective dosing schedule on efficacy of beclomethasone dipropionate aerosol in chronic asthma. Am Rev Respir Dis 1985;131:732-6.

13 Neville A, Palmer JBD, Gaddie J, May CS, Palmer KNV, Murchison LE. Metabolic effects of salbutamol: comparison of aerosol and intravenous administration. $B M \mathcal{F}$ $1977 ; 1: 413-4$. 